\title{
Lake heat content and stability variation due to climate change: coupled regional climate model (REMO)-lake model (DYRESM) analysis
}

\author{
Stefan WEINBERGER, ${ }^{1 *}$ Mark VETTER ${ }^{2}$ \\ ${ }^{1}$ Department of Geography, Faculty of Geosciences, University of Munich, Luisenstrasse 37, 80333 München; ${ }^{2}$ Faculty of Information \\ Management and Media, Karlsruhe University of Applied Sciences, Moltkestrasse 30, 76133 Karlsruhe, Germany \\ *Corresponding author: s.weinberger@geographie.uni-muenchen.de
}

\begin{abstract}
Climate change-derived higher air temperatures and the resulting increase in lake surface temperatures are known to influence the physical, biological and chemical processes of water bodies. By using hydrodynamic lake models coupled with regional climate models the potential future impact of a changing climate can be investigated. The present study hence elucidates limno-physical changes at the peri-Alpine, 83-m deep, currently dimictic Ammersee in southeastern Germany, both to underline the role of lakes as sentinels of climate change and provide a sound basis for further limnological investigations. This was realised by using water temperatures simulated with the hydrodynamic model DYRESM for the period 2041-2050, based on the results of the regional climate model REMO (IPCC A1B emission scenario). Modelling of future heat content resulted in a projected increase in the upper $3 \mathrm{~m}$ of the epilimnion from end of March to mid-November, whereas a decrease in future total heat content (January-December) of the entire water column was simulated compared to that observed in 1997-2007. Lake thermal stability is projected to be higher in the period 2041-2050 than in 1985-2007. Stratification is expected to occur earlier and to last longer in the future than the pattern observed in 1985-2007. The future mean MayJune depth of the thermocline is simulated to be situated above its past average vertical position, whereas an increase of mean thermocline depth is projected for the beginning of August to October. Furthermore, the mean May-October thickness of the metalimnion is simulated to increase. Additionally, we investigated the sensitivity of these limno-physical results to changes in the model parameter light extinction coefficient which determines how the solar radiation is absorbed by the lake water. The elucidation of physical changes at Ammersee by means of a regional climate model provides a sound basis on which to face the new challenges of lake modelling.
\end{abstract}

Key words: DYRESM, Lake Ammersee, regional climate model REMO, aquatic ecosystem, stratification, water management.

Received: January 2013. Accepted: September 2013.

\section{INTRODUCTION}

The impact of climate change-driven increases in air temperature on lake water temperatures has been the subject of numerous studies in recent years (Livingstone, 2003; Adrian et al., 2009; Fang and Stefan, 2009; Williamson et al., 2009a; Ludovisi and Gaino, 2010; Schneider and Hook, 2010; Weinberger and Vetter, 2012). The resulting heating of the vertical water column in turn leads to substantial changes in the physical properties of the lake (Gaiser et al., 2009; Ambrosetti et al., 2010; Braig et al. 2010; Rempfer et al., 2010), more precisely in terms of mixing processes, stratification characteristics (Danis et al., 2004; Ambrosetti and Barbanti, 2005; Austin and Colman, 2008; MacIntyre et al., 2009; MacKay et al., 2009; Rimmer et al., 2011) and heat content (Hondzo and Stefan, 1993; Dokulil et al., 2006; Vetter and Sousa, 2012). Investigations dealing with these limno-physical changes are crucial, as the latter directly influence nearly all biological and chemical processes. For example, substantial trophic- and species-dependent changes are caused by shifts in the climate regime of lakes (Kirilova et al., 2009; Wagner and Adrian, 2009; Rinke et al., 2010;
Gallina et al., 2011), while the distribution of nutrients and oxygen is also affected (Braig et al., 2010; Rempfer et al., 2010; Vetter and Sousa, 2012).

In order to improve our understanding of the aforementioned physical, biological and chemical processes, it is necessary to use hydrodynamic and ecological lake models (Huber et al., 2008; Fang and Stefan, 2009; Ambrosetti et al., 2010) in addition to field studies and statistical analysis of historical lake data (Peeters et al., 2002). These mathematical models are able to simulate the future impact of a changing climate on lake ecosystem and water quality (Perroud et al., 2009). Even though others have already made this point, there remains a need for substantial studies investigating these environmental consequences. Such investigations should utilise data and information derived from regional climate models, e.g. REMO (Jacob et al., 2007), which represent the only tools able to satisfactorily estimate future rates of climate change (Samuelsson, 2010). The simulations produced by these climate models are based on different IPCC emission scenarios (Nakicenovic et al., 2000; Solomon et al., 2007). However, information gaps remain in modelling 
impacts on limnological ecosystems (MacKay et al., 2009); studies using regional climate model data were largely unavailable in the past (Bates et al., 2008).

As a result of the above-mentioned issues, in Weinberger and Vetter (2012) a first hydrodynamic simulation approach was implemented using the hydrodynamic model DYRESM (Imberger and Patterson, 1981; Imerito, 2007), based on the results of the regional climate model REMO for Ammersee. Initially the one-dimensional model DYRESM was calibrated and validated to simulate lake vertical thermal distribution, with meteorological data from the regional climate model REMO (IPCC A1B emission scenario) then employed as input data for DYRESM and a simulation run carried out for the period 2041-2050. The produced results regarding potential future water temperature changes thus provide the basis of the present study, making it possible to address the limnophysical impacts of climate change in particular.

The study site, Ammersee, is a peri-Alpine, $83-\mathrm{m}$ deep, currently dimictic lake located $30 \mathrm{~km}$ southwest of the Munich metropolitan area. The third largest lake in Bavaria and very important for regional tourism and fisheries, Ammersee has a surface area of $46.6 \mathrm{~km}^{2}$, a water volume of $1.75 \times 10^{9} \mathrm{~m}^{3}$ and a glacial morphologic origin. Ammersee was selected as the study site because of its geogenic, climatic, geographic and limnological characteristics, which are representative of many other lakes in the northern foothills of the Alps. The lake freezes over in winter in some years (Danis et al., 2004). It has one main inflow called the Ammer, three smaller inflows known as the Windach, Rott and Kienbach, and one main outflow called the Amper. The Ammersee would naturally be oligotrophic (Kucklentz, 2001; Vetter and Sousa, 2012), but due to intensive land use in the catchment area from around 1950, the lake became mesotrophic. In the last 20 years Ammersee has undergone re-oligotrophication after the establishment of specialised sewerage (Ernst et al,. 2009), but whether this trend will continue under projected climate change conditions is not clear (Vetter and Sousa, 2012). Different estimations have been postulated regarding future limno-physical and ecological development as a consequence of anthropogenic and climatic impacts. Danis et al. (2004), for example, projected Ammersee to undergo a dramatic and persistent lack of mixing, starting in around 2020; the resulting lack of oxygenation would irreversibly destroy the lake's deepwater fauna. Joehnk and Umlauf (2001) mentioned the importance of modelling oxygen conditions in Ammersee. These environmental risks, as well as the desire to improve the existing level of knowledge regarding the impact of climate change on limnological systems and their catchment area (Niedda and Pirastru, 2013), demonstrate the necessity of new modelling studies using well-prepared regional climate model data (Mooij et al. 2010;
Trolle et al., 2011). In doing so it is then possible to estimate the lake's ecological future and support subsequent water quality management. Studies employing DYRESM have been able to effectively simulate future Ammersee water temperature changes (Weinberger and Vetter, 2012; Bueche and Vetter, 2013), with the model now established as a sound basis for the deduction of prospective limnophysical variations.

The objective of the present study was to therefore use the predicted water temperatures simulated by the hydrodynamic model DYRESM, based on the results of the regional climate model REMO (IPCC A1B emission scenario), to calculate i) the heat content of Ammersee for the years 2041-2050; and ii) the thermal stability of the lake water column for the same period. These results were then assessed and compared to past limno-physical properties of Ammersee. In addition iii), changes in the duration of thermal stratification were investigated, while iv) the depth of the thermocline as well as the depth of the upper and lower metalimnion were also deduced. Finally, v) the sensitivity of the limno-physical results to the model parameter light extinction coefficient was analysed. To underline the motivation for this study it should be said, that the elucidation of physical changes by means of a regional climate model at Ammersee can provide further important knowledge with which to estimate the potential impact of climate change on water bodies in the northern foothills of the Alps.

\section{METHODS}

The present study used the one-dimensional hydrodynamic model DYRESM (v4.0.0-b2), developed by the Centre for Water Research at the University of Western Australia. Able to predict the vertical distribution of temperature, salinity and density in lakes and reservoirs (Imberger and Patterson, 1981), DYRESM is a process-based model with a Lagrangian layer scheme, which means that the horizontal layers are adjusted to stay within user-defined limits (Imberger and Patterson, 1981; Antenucci and Horn, 2002). Layer mixing appears when the turbulent kinetic energy in the topmost horizontal layer, produced via convective overturn, wind stirring and shearing (Perroud et al., 2009), exceeds a potential energy threshold. DYRESM has been applied to different study areas around the world (Han et al., 2000; Gal et al., 2003; Romero et al., 2004; Trolle et al., 2008; Perroud et al., 2009; Rinke et al., 2010) and is particularly suitable for the simulation of longer periods. In comparison to other one-dimensional lake models, DYRESM is able to satisfactorily reproduce the variability of both water temperature profiles and seasonal thermoclines (Perroud et al., 2009). DYRESM can also be run either in isolation for hydrodynamic studies, or coupled to an aquatic ecological model, e.g. CAEDYM, for the investigation of biological 
and chemical processes (Imerito, 2007). For the analysis of Ammersee, DYRESM was carefully calibrated (for the period 2004-2007) and validated (1993-1999) taking into account simulated and measured water temperatures. Furthermore, to determine the quality of the calibration and validation process, modelled and observed data were compared via the use of regression analysis and the quality criteria mean absolute error (MAE) and root mean square error (RMSE) (Legates and McCabe, 1999). As small mean absolute errors (0.96-1.61 K) and root mean square errors $(1.42-1.96 \mathrm{~K})$ were observed, as well as high coefficients of determination (0.71-0.96) at all depths, the selected hydrodynamic model was considered able to identify the potential drawbacks of climate change on the lake and thus provide the basis for subsequent coupled aquatic ecological modelling.

Nevertheless, it has to be said that DYRESM is originally not able to continue the simulation process when water temperatures decrease below $0^{\circ} \mathrm{C}$. Hence, at Ammersee, we used a modified version with freezing avoidance, which means that negative values of water temperature were set back to $0^{\circ} \mathrm{C}$ to ensure a continuous and stable simulation. Although, because of this, ice cover is not included in the model directly, the introduced error is small for large peri-Alpine lakes as they rarely freeze and the cooling-down is not very intense. Full ice cover was observed at Ammersee in 15 years from 1934 to 1971 (Danis et al., 2004). For the period from 1971 to 2012 there are no publications dealing with ice cover available, but according to own observations and analyses the lake has frozen over in 5 years. Moreover, the effect of freezing avoidance diminishes throughout the season when surface temperatures are approaching a value corresponding to the equilibrium energy exchange between the lake and the atmosphere (Weinberger and Vetter, 2012). More details regarding the comprehensive calibration and validation of DYRESM for Ammersee can be also found in Bueche and Vetter (2013).

When estimating the impact of climate change on lakes, it is generally advisable to use meteorological input data produced by regional climate models. The climate data employed in the present study were acquired from the regional climate model REMO (Jacob et al., 2007), which was selected because its cell calculation size of $10 \times 10 \mathrm{~km}$ was considered suitable for analysis of the Ammersee area. The REMO simulation provides variables including short-wave radiation, air temperature, precipitation, wind speed, vapour pressure, total cloud cover and relative humidity, all of which have a strong influence on the heat budget of a lake. Long-wave radiation was estimated from atmospheric conditions using cloud cover fraction (Imerito, 2007). Use of REMO data also requires the implementation of bias correction; this process had already been carried out in an earlier study by comparing previously-measured meteorological data from the study area (covering the period 1990-2006) with those simulated by the regional climate model (20012017) (Weinberger and Vetter, 2012). Based on these comparisons, statistical relationships for each month could then be determined that were relevant to the correction of calculated future climatic conditions. For example, when correcting the air temperature values derived from the REMO model, an absolute correction value was adapted to the daily mean air temperatures, whereas the correction of daily precipitation sums was implemented relatively via the use of a multiplication factor (Piani et al., 2009; Mudelsee et al., 2010; Terink et al., 2010). Our investigations demonstrate that the use of regional climate models such as REMO in hydrodynamic model studies (after obligatory bias correction) is a practicable way of estimating future impacts of climatic warming on lake ecosystems in the northern foothills of the Alps.

The research presented in Weinberger and Vetter (2012) and taken as basis for this study, includes such a simulation for Ammersee, based on the IPCC A1B emission scenario for the period 2041-2050. The A1B emission scenario was selected due to the fact that it assumes balanced use of all available energy sources (Nakicenovic et al., 2000; Solomon et al., 2007). In this scenario, the global mean air temperature is predicted to increase by about $3 \mathrm{~K}$ between 1990 and 2100. Future climate change conditions in the present study were also derived from the aforementioned regional climate model REMO; the vertical thermal distribution in Ammersee was then simulated for the period 2041-2050 using bias-corrected REMO meteorological data as input values for the hydrodynamic model DYRESM. This simulation method is, as mentioned previously, now established as a sound basis on which to both deduce potential future physical changes, such as those mentioned in the Introduction, and to provide further important knowledge which can be used to estimate the potential impact of climate change.

To clarify which are the main drivers for changes in limno-physical conditions in the future we investigated sensible, latent and radiative heat fluxes. At Ammersee, the sensitivity of the hydrodynamic model DYRESM to changes in meteorological input variables and to changes in water temperatures of the inflow was analysed. Thereby the greatest influences on the heat budget and on the dynamics of the lake were detected for modifications of air temperature and wind speed (Bueche and Vetter, 2013). The variable wind speed is known to influence mixing and the exchange of both latent and sensible heat at the water surface (Livingstone, 2003). The fact that the variable air temperature has the greatest ramifications was also detected by Trolle et al. (2011), who included only a simple air temperature offset in representing future meteorological conditions in their lake modelling study. All the 
changes in monthly mean air temperatures simulated by the model REMO (A1B scenario) until the period 20412050 at Ammersee can be seen in Tab. 1. To elucidate that there are also existing more pessimistic emission scenarios than A1B, in Tab. 1 we additionally show bias-corrected air temperatures based on the emission scenario A2. This scenario assumes that the global mean air temperature will increase by about $3.5 \mathrm{~K}$ between 1990 and 2100 due to regionally oriented economic development and a continuously increasing world population (Nakicenovic et al., 2000). For further limno-physical research at Ammersee, as mentioned before, in this study we take the scenario A1B as basis, which is based on assumptions that are more realistic.

Nevertheless, the potential effects of other meteorological variables and processes should not be neglected. For example cloud cover can affect both long-wave and short-wave radiation, while relative humidity influences the exchange of latent heat (Livingstone 2003, Trolle et al. 2011). Hence these variables, provided by the regional climate model REMO, were also taken into account in our study at Ammersee. To compare the simulated hydrodynamic results with data obtained in the field, a series of water temperature and conductivity measurements were used which have been collected at Ammersee since 1976, with regular readings carried out since 1985 . These data are collected at the deepest point of the lake by the Bavarian Environmental Agency. Measurements within the epilimnion are taken every $2 \mathrm{~m}$, in the metalimnion every 3 $\mathrm{m}$ and in the hypolimnion every $10 \mathrm{~m}$. The time step of data collection has varied, but in general measurements have been carried out at least every month. This field data both provided a sound basis for the calibration and validation of the hydrodynamic model DYRESM employed in Weinberger and Vetter (2012), and was also used to cal-

Tab. 1. Monthly mean air temperature $\left({ }^{\circ} \mathrm{C}\right)$ at Lake Ammersee measured in the past and simulated for the future by the model REMO.

\begin{tabular}{lccc}
\hline Month & $1990-2006$ & 2041-2050 A1B & 2041-2050 A2 \\
\hline January & -0.4 & 1.9 & 1.8 \\
February & 0.1 & 1.9 & 1.2 \\
March & 3.1 & 4.4 & 4.7 \\
April & 6.0 & 6.8 & 8.2 \\
May & 11.5 & 12.4 & 13.1 \\
June & 14.5 & 14.8 & 15.7 \\
July & 16.3 & 16.2 & 17.2 \\
August & 16.4 & 17.2 & 16.6 \\
September & 12.0 & 11.7 & 13.9 \\
October & 8.4 & 9.4 & 9.2 \\
November & 2.9 & 4.6 & 4.5 \\
December & 0.0 & 1.3 & 1.1 \\
\hline
\end{tabular}

Values are bias-corrected and based on emission scenarios A1B and A2. culate past values of limno-physical variables for the present study. Total lake heat content (W) can be calculated by summing the heat content of single layers (from lake surface to lake bottom) based on their mean water temperatures (Schwoerbel and Brendelberger, 2005):

$$
\mathbf{W}=\int_{0}^{\mathbf{z}_{\max }} \mathbf{T}(\mathbf{z}) \mathbf{c}_{\mathbf{p}}(\mathbf{z}) \boldsymbol{\rho}(\mathbf{z}) \mathbf{A}(\mathbf{z}) \mathbf{d}(\mathbf{z})
$$

where $\mathrm{T}(\mathrm{z})$ is the mean water temperature $\left({ }^{\circ} \mathrm{C}\right)$ at depth $\mathrm{z}, \mathrm{c}_{\mathrm{p}}(\mathrm{z})$ is the specific heat capacity $\left(\mathrm{kJ} \mathrm{kg}^{-1} \mathrm{~K}^{-1}\right)$ at depth $z, \rho(z)$ is the density of water $\left(\mathrm{kg} \mathrm{m}^{-3}\right)$ at depth $\mathrm{z}, \mathrm{A}(\mathrm{z})$ is the isobath plane $\left(\mathrm{m}^{2}\right)$ at depth $\mathrm{z}$ and $\mathrm{d}(\mathrm{z})$ is the depth interval. In addition to mean total lake heat content, heat content was also calculated for the layers from 0-3, 3-10 and below $10 \mathrm{~m}$. To make it easier to compare the results for Ammersee with results of similar studies, the heat content is additionally given in terms of volume-weighted mean (VWM) temperatures.

To derive the thermal stability of the water column, values of Schmidt stability were determined according the following equation:

$$
S=g A_{0}^{-1} \int_{0}^{z_{\max }}\left(z-z^{*}\right)\left(\rho(z)-\rho^{*}\right) A(z) d(z)
$$

where $A_{0}$ is lake surface area $\left(\mathrm{m}^{2}\right), \mathrm{A}(\mathrm{z})$ is lake area $\left(\mathrm{m}^{2}\right)$ at depth $z, \rho(z)$ is density $\left(\mathrm{kg} \mathrm{m}^{-3}\right)$ calculated from temperature at depth $z, \rho^{*}$ is the volume-weighted mean density of the water column $\left(\mathrm{kg} \mathrm{m}^{-3}\right), \mathrm{z}^{*}$ is the depth (m) at which mean density occurs, $\mathrm{d}(\mathrm{z})$ is the depth interval $(\mathrm{m})$ and $\mathrm{g}$ is acceleration due to gravity $\left(\mathrm{m} \mathrm{s}^{-2}\right)$. Representing the work that would be required to transform a thermally stratified lake into a lake characterised by isothermal conditions, the Schmidt stability value has been used to account for the intensity of summer stratification in a number of lake studies (Ambrosetti and Barbanti, 2005; Gaiser et al., 2009; Braig et al., 2010). Other climate change impact studies that have used Schmidt stability as a measure of lake stratification include Livingstone (2003), Coats et al. (2006), Jankowski et al. (2006) and Rempfer et al. (2010). Calculation of Schmidt stability requires the determination of lake water density and conductivity. For Ammersee, the density at different depths was calculated according to Chen and Millero (1986), while conductivity was determined using the relationship between temperature, density and water pressure in the water column (UNESCO 1987).

Also deduced was the duration of lake thermal stratification for the simulated period 2041-2050; again this was then compared to the observed duration of stratification in the past (1985-2007). The present study follows the work of Birge (1897), who defined the thermocline as the region in the vertical profile of a lake, where the temperature decreases by $1 \mathrm{~K}$ per metre of depth. If such a difference in temperature is measured or simulated, the 
lake is considered stratified at that time. As per Hutchinson (1957), the thermocline was also considered as the depth plane at which the largest relative change in water temperature occurs. Using observed past water temperatures and simulated water profiles for the period 20412050 , it was possible to detect changes in the depth of the thermocline potentially due to climate change. Definition of the upper and lower borders of the metalimnion was carried out in the same manner as the deduction of the duration of thermal stratification, i.e. following Birge (1897). Accordingly, the metalimnion was considered to be the region in the vertical profile of a lake within which the temperature decreases by $1 \mathrm{~K}$ per metre of depth.

To assess whether the differences between the estimated changes for the future, deduced from the hydrodynamic model, and the measured historical data are statistically significant, we conducted Welch two-sample $t$-tests for the variables duration of thermal stratification, depth of thermocline and Schmidt stability. After calculation of limno-physical variables for the future, we also investigated the sensitivity of these results to changes in the parameter light extinction coefficient (LEC) of the water, which has to be set in the input files of the hydrodynamic model DYRESM. This parameter determines how the solar radiation is absorbed by the lake water and directly influences the heating of the epilimnion (Imberger and Patterson 1981). Hence the LEC was already used for the calibration of the model DYRESM at Ammersee and at the end set to $0.25 \mathrm{~m}^{-1}$ (Weinberger and Vetter, 2012). For our sensitivity analysis in the recent study we first reduced the LEC by $10 \%$ to a value of $0.225 \mathrm{~m}^{-1}$ and afterwards raised the LEC by $10 \%$ to a value of $0.275 \mathrm{~m}^{-1}$.

\section{RESULTS}

\section{Heat content}

Lake heat content was calculated for the layers from $0-3,3-10$, below $10 \mathrm{~m}$ and for the whole lake. This was achieved using both simulated (future) and measured (past) data. Fig. 1 presents a comparison of the resulting mean heat content for each month for the periods 20412050 and 1997-2007.

Analysis of graph a in Fig. 1 reveals that the heat content of the upper $3 \mathrm{~m}$ of the epilimnion is predicted to be higher in the future from end of March to mid-November. The highest increase is expected during June to October, with the maximum heat content simulated at $12 \mathrm{GJ}$ or
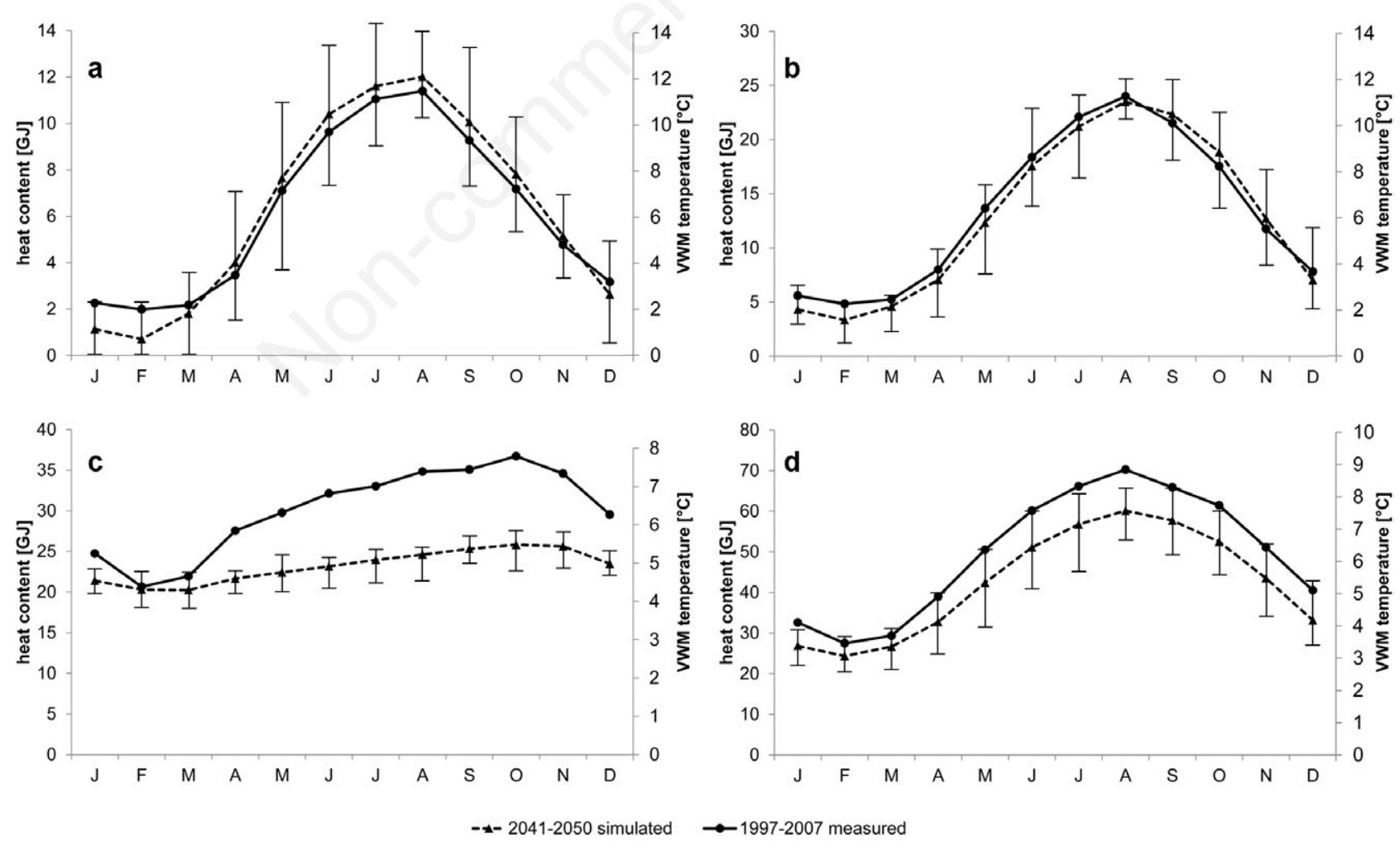

Fig. 1. Monthly mean heat content and respective volume-weighted mean (VWM) temperature at a depth of 0-3 (a), 3-10 (b), below 10 $\mathrm{m}$ (c) and for the whole lake (d), calculated for Ammersee from measured (1997-2007) and simulated data (2041-2050, A1B emission scenario). The error bars show the maximum and the minimum of the simulated values used to calculate the simulated monthly mean. 
$12^{\circ} \mathrm{C}$ (volume-weighted mean (VWM) temperature) in August. The measured maximum was also observed in August, at $11.5 \mathrm{GJ}$ (VWM temperature: $11.5^{\circ} \mathrm{C}$ ). Winter values are projected to be lower than in the past. Between 3 and $10 \mathrm{~m}$ depth (Fig. 1b), an increase in heat content is predicted only for September, October and November; an obvious decrease is estimated for January and February, while in the remaining months a merely slight decrease is visible from the past to the period 2041-2050. Below 10 $m$ depth (Fig. 1c), a clear decrease in January as well as from April to December lake heat content is simulated, with a maximum decrease of around 10 GJ (VWM temperature: around $2^{\circ} \mathrm{C}$ ) projected for October. February lake heat content is expected to remain nearly constant, whereas March values are predicted to decrease only slightly in the future. Analysis of total lake heat content (Fig. 1d) reveals decreasing values for the whole year. Maximum total heat content for Ammersee was observed in August for both measured and simulated values, at 70 GJ (VWM temperature: $9^{\circ} \mathrm{C}$ ) and 60 GJ (VWM temperature: $7.5^{\circ} \mathrm{C}$ ), respectively.

When calculating the heat content, the process of freezing avoidance during the simulation run, as mentioned in the Methods, should be considered. Thereby negative values of water temperature are set back to $0^{\circ} \mathrm{C}$ to ensure a continuous and stable simulation. During eleven years of calibration and validation (2004-2007 and 1993-1999) at Ammersee (Weinberger and Vetter, 2012), water temperatures were set back to $0^{\circ} \mathrm{C}$ by the model
DYRESM on 49 days, whereas during the 10 years-model run from 2041 to 2050 the freezing avoidance was set up on 63 days.

\section{Thermal stability}

Fig. 2 presents a comparison of box-and-whisker plots for observed (past: 1985-2007) and simulated (20412050) Schmidt stability data for each month relevant to thermal stratification. The boxes in Fig. 2 consist of median and upper and lower quartile $\left(25^{\text {th }}\right.$ and $75^{\text {th }}$ percentile), with upper and lower whiskers and some outliers also illustrated. The end of the upper whisker in the present case study was set at the $97.5^{\text {th }}$ percentile, and the end of the lower whisker at the $2.5^{\text {th }}$ percentile of the data. Outliers were defined as only those values lying beyond the threshold of 1.5 times the interquartile range (IQR) above the $75^{\text {th }}$ percentile.

It is apparent from analysis of Fig. 2 that lake thermal stability is expected to increase in the future for each month from April to November, with the simulated $25^{\text {th }}$ percentile, median and $75^{\text {th }}$ percentile lying above the respective observed field data values. Indeed, in April and August the projected $25^{\text {th }}$ percentiles are nearly as high as the measured $75^{\text {th }}$ percentiles for the same months. Furthermore, all upper and lower whiskers, with the exception of those for October and November, are projected to be higher in the future. Also included were the minimum and maximum Schmidt stabilities, as well as the upper outliers (Tab. 2).

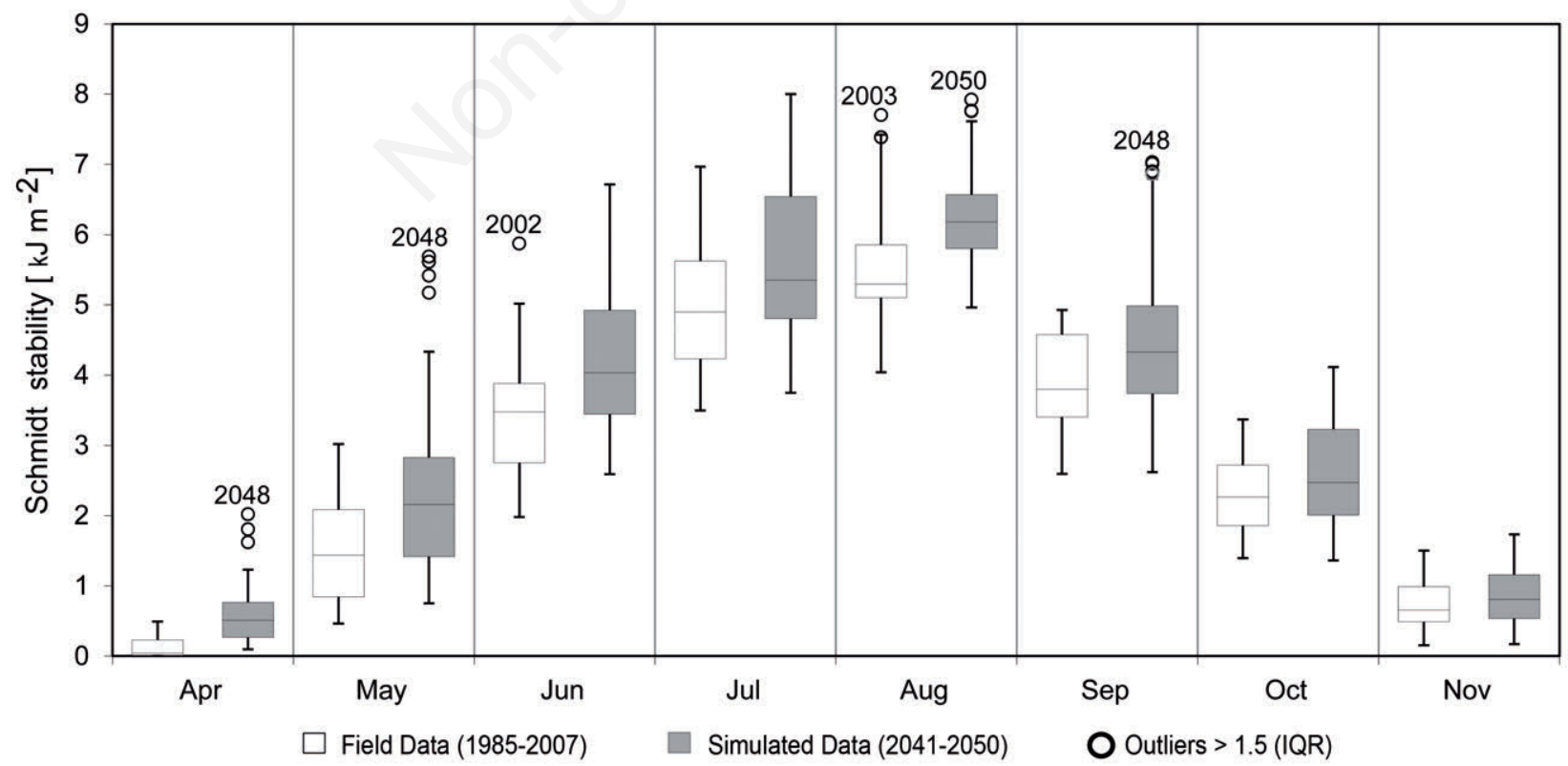

Fig. 2. Comparison of calculated Schmidt stabilities for Ammersee, box-and-whisker chart for field (1985-2007) and simulated data (2041-2050, A1B emission scenario) with outliers for different months. Maximum outliers are specifically marked by year number. 
The number of upper outliers as defined in the boxplot chart is also predicted to increase in the future (20412050), with 3 occurring in April, 4 in May, 3 in August and 5 in September. During the period 1985 to 2007, only 1 outlier was observed in June $\left(5.87 \mathrm{kJm}^{-2}\right.$ in 2002$)$ and 2 outliers in August (maximum outlier $7.70 \mathrm{kJm}^{-2}$ in 2003). All upper outliers as well as the year number corresponding to the maximum outliers are also shown in Fig. 2. While minimum Schmidt stabilities are simulated to remain similar to those observed in the past, monthly maximum values are expected to increase clearly, with the exception of those in August and November. In May and September the increase in maximum thermal stability is expected to be higher than $2 \mathrm{kJm}^{-2}$, while the maximum predicted monthly value of $8.59 \mathrm{kJm}^{-2}$ is projected to occur in July (Tab. 2).

To assess whether these changes in Schmidt stability are statistically significant, we conducted a Welch twosample $t$-test (Tab. 3). Thereby it becomes obvious that the increase in thermal stability is highly significant from April to October.

\section{Duration, onset and end of thermal stratification}

Another aspect of possible limno-physical change resulting from increasing water temperatures is the duration and timing of onset of thermal stratification. The simulated stratification behaviour of Ammersee for the period 20412050 was thus compared with observed stratification data for the period 1985-2007. During the former, thermal stratification is modelled to commence on average on the $27^{\text {th }}$ of April and end on the $8^{\text {th }}$ of November, with the earliest date of onset the $16^{\text {th }}$ of April and the latest end the $19^{\text {th }}$ of November. The average date of observed stratification according to field data was the $15^{\text {th }}$ of May, with the average end of stratification date the $10^{\text {th }}$ of October. The earliest historic onset was observed on the $7^{\text {th }}$ of May, and the latest end on the $22^{\text {nd }}$ of October. The longest period of stratification during the years 1985-2007 was 169 days, whereas the shortest lasted for only 127 days. The duration of thermal stratification at Ammersee is simulated to increase significantly in the future (Welch two-sample $t$-test, $\mathrm{P}=0.0011$ ), with a maximum of 204 days and a minimum of 162 days. A summary of the obtained data is provided in Tab. 4 .

Fig. 3 displays the duration of simulated thermal stratification for each year during the period 2041-2050; the vertical black lines represent the observed average beginning and end dates of stratification recorded between 1985 and 2007. Analysis of Fig. 3 and Tab. 4 reveals not only a projected increase in the duration of thermal stratification, but also that the shortest period of stratification in the future is estimated to be nearly equal to the longest period measured in the past. In summary, thermal stratification of Ammersee is expected to occur earlier and to last longer than previously recorded.
When looking at Fig. 3 and Tab. 4, it is very important to consider that it is not possible to predict dates of onset and end of thermal stratification exactly. We are only able to deduce these dates directly from the simulated water temperatures using a daily model time step. Thereby we follow Birge (1897), as mentioned above and take into account mean dates during each period.

\section{Depth of thermocline and metalimnion}

Any changes in the position of the thermocline are expected to be very important for the ecology of water bodies. In the present study two methods of analysis were

Tab. 2. Number of upper outliers, maximum and minimum values $\left(\mathrm{kJ} \mathrm{m}^{-2}\right)$ of Schmidt stability for the past and the future.

\begin{tabular}{lcccccc}
\hline Month & \multicolumn{2}{c}{ Past $(1985-2007)$} & \multicolumn{3}{c}{ Future $(2041-2050)$} \\
\cline { 2 - 7 } & Outliers & Max & Min & Outliers & Max & Min \\
\hline April & 0 & 0.51 & 0 & 3 & 2.02 & 0.03 \\
May & 0 & 3.37 & 0.14 & 4 & 5.69 & 0.58 \\
June & 1 & 5.87 & 1.96 & 0 & 7.06 & 2.35 \\
July & 0 & 7.22 & 3.50 & 0 & 8.59 & 3.17 \\
August & 2 & 7.70 & 3.80 & 3 & 7.92 & 4.51 \\
September & 0 & 4.96 & 2.56 & 5 & 7.03 & 2.31 \\
October & 0 & 3.64 & 1.28 & 0 & 4.56 & 1.03 \\
November & 0 & 1.51 & 0.13 & 0 & 1.87 & 0 \\
\hline
\end{tabular}

Tab. 3. Comparison of simulated Schmidt stability and depth of thermocline (2041-2050) vs measured values of field data, using a Welch two-sample $t$-test.

\begin{tabular}{lcc}
\hline & Schmidt stability $(t / \mathrm{df} / \mathrm{P})$ & Depth of thermocline $(t / \mathrm{df} / \mathrm{P})$ \\
\hline April & $11.0 / 54 /<0.0001$ & \\
May & $4.4 / 46 /<0.0001$ & $13.6 / 45 /<0.0001$ \\
June & $5.2 / 42 /<0.0001$ & $8.9 / 42 /<0.0001$ \\
July & $3.4 / 49 /=0.0015$ & $0.3 / 58 /=0.7762$ \\
August & $5.3 / 40 /<0.0001$ & $2.4 / 55 /=0.0176$ \\
September & $4.1 / 51 /=0.0002$ & $8.3 / 56 /<0.0001$ \\
October & $2.9 / 43 /=0.0058$ & $10.2 / 48 /<0.0001$ \\
November & $1.2 / 44 /=0.2303$ & \\
\hline
\end{tabular}

$d f$, degree of freedom.

Tab. 4. Dates and onset of thermal stratification for the past (1985-2007, observed) and derived directly from the model DYRESM for the future (2041-2050).

\begin{tabular}{lcc}
\hline & $1985-2007$ & $2041-2050$ \\
\hline Earliest beginning (date) & 7 May & 16 April \\
Latest end (date) & 22 October & 19 November \\
Longest period (days) & 169 & 204 \\
Shortest period (days) & 127 & 162 \\
\hline
\end{tabular}


carried out: the first comparing the mean depth of the thermocline as defined by Hutchinson (1957) using recorded (1985-2007) and simulated data (2041-2050) for each month from mid-May to mid-October, and the second contrasting the mean depth and mean thickness of the metalimnion as per Birge (1897) for the same periods. The results can be seen in Fig. 4.

The position of the thermocline relocates towards the lake bottom between May and October in both recorded and simulated data. The minimum mean depth of the thermocline in the past was measured in May at around $6 \mathrm{~m}$, while the projected depth during the same month is around $4 \mathrm{~m}$. The maximum mean recorded depth was observed at around $12 \mathrm{~m}$ and the modelled value for 20412050 at around $13 \mathrm{~m}$. Between May and June the mean depth of the thermocline is projected to lie above its historically-recorded position, although in July the vertical position of the thermocline is modelled to remain in a similar range to its previous depth. However, for the period from the beginning of August to October, an increase of the mean depth of thermocline is predicted. Using a Welch two-sample t-test, we investigated that the changes in depth of thermocline are highly significant with the exception of July (Tab. 3). The mean thickness of the metalimnion is simulated to increase for the whole period between May and October, with the largest expanse of 8 $\mathrm{m}$ occurring at the end of August. In contrast, the largest thickness of $6 \mathrm{~m}$ during the period 1985 to 2007 was observed in July.

The mean depth of the upper and lower delineation of the metalimnion increases between May and October in both recorded and simulated data. The recorded and pro-

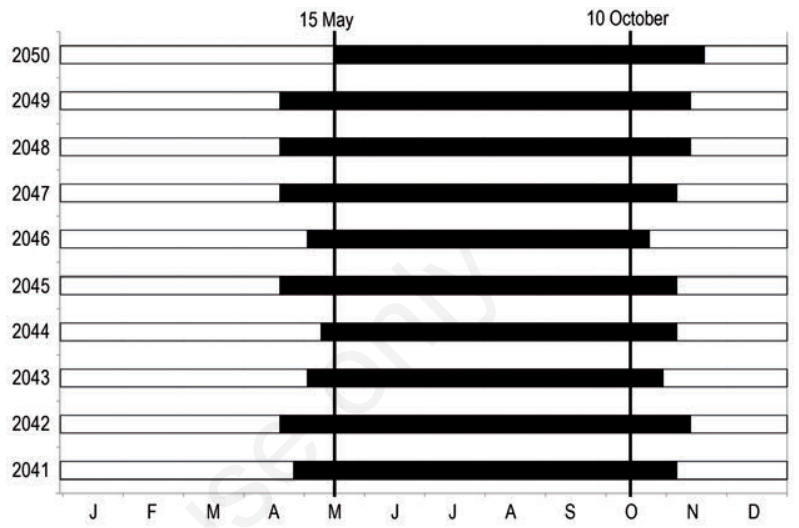

Fig. 3. Expected duration of lake thermal stratification deduced from simulated DYRESM data (2041-2050, A1B emission scenario), together with an illustration of the observed average start and end of stratification (1985-2007).

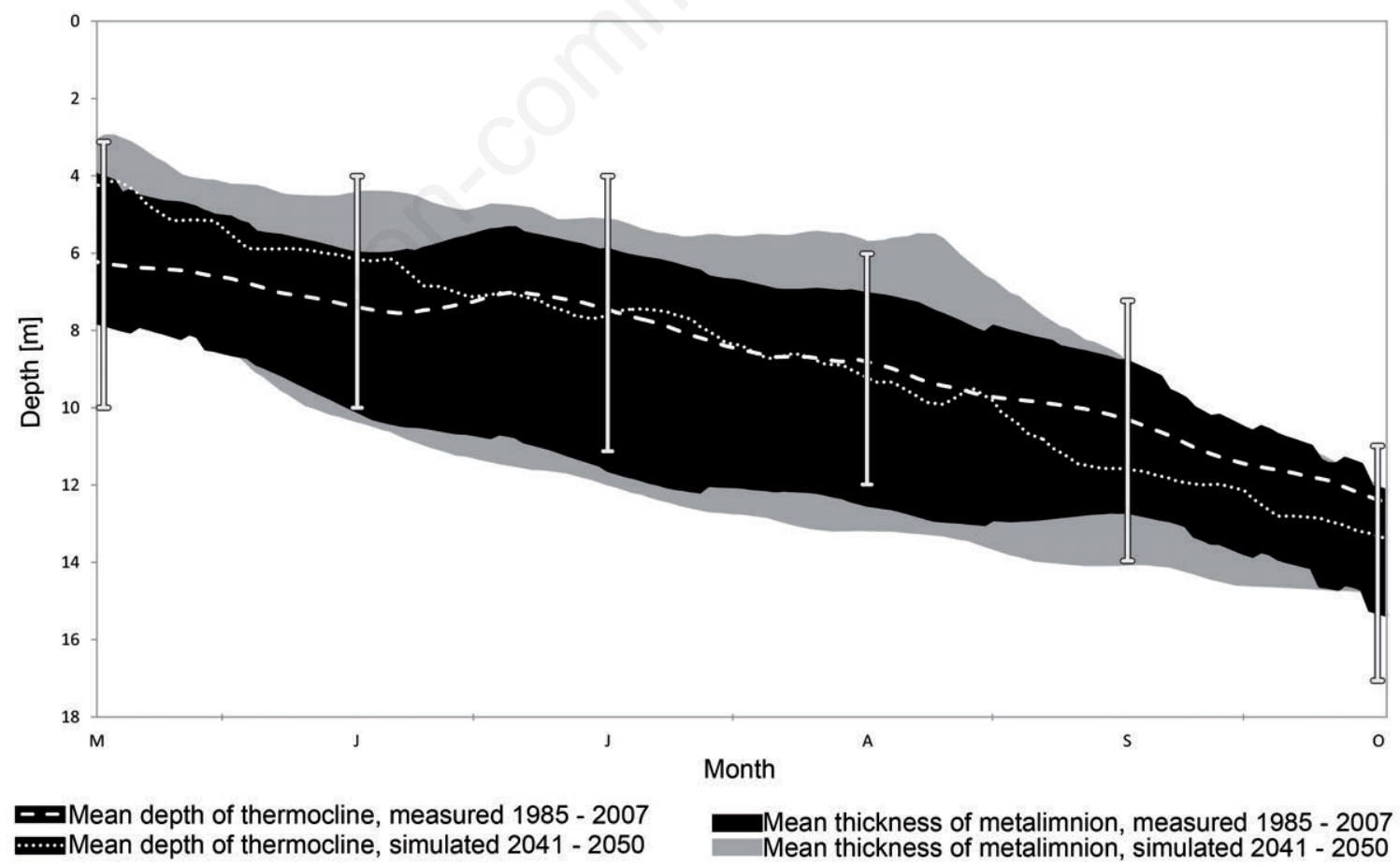

Fig. 4. Mean depth of thermocline and mean thickness of metalimnion deduced from field (1985-2007) and simulated data (2041-2050, A1B emission scenario). The error bars show the maximum and the minimum of the simulated values used to calculate the monthly mean of thermocline depth. 
jected minimum mean depth of the upper border of the metalimnion was observed at $4 \mathrm{~m}$ and $3 \mathrm{~m}$, respectively, with the maximum mean depth at around $12 \mathrm{~m}$ in both periods. The minimum mean depth of the lower border of the metalimnion was around $8 \mathrm{~m}$ for both past and predicted data, with the maximum mean depth between 15 and $16 \mathrm{~m}$ for $1985-2007$ and between 14 and $15 \mathrm{~m}$ for 2041-2050.

\section{Sensitivity to light extinction coefficient}

The water temperatures simulated by the model DYRESM and the calculated limno-physical variables for the future are sensitive to the parameter light extinction coefficient (LEC) of the water, which has to be set in the input files of the hydrodynamic model DYRESM. For our sensitivity analysis we first reduced the LEC by $10 \%$ to a value of $0.225 \mathrm{~m}^{-1}$. This resulted in a slight decrease of modelled surface water temperatures in spring and summer as well as increasing water temperatures in the metalimnion and hypolimnion (below $10 \mathrm{~m}$ ) and a higher heat content of the whole lake (Fig. 5). This in turn resulted in lower stratification and in the following more heat was able to reach the deeper layers. Afterwards we raised the LEC by $10 \%$ to a value of $0.275 \mathrm{~m}^{-1}$. As a consequence, we were able to observe just the opposite. This implies that the modelled surface water temperatures in spring and summer slightly increased and decreasing water temperatures were observed in the metalimnion and hypolimnion (below $10 \mathrm{~m}$ ), which resulted in a lower heat content of the whole lake (Fig. 5) and in stronger stratification of the water column.

\section{DISCUSSION}

The following section discusses the results of the present study regarding possible physical and ecological consequences, comparing them to the outcomes of similar limnological investigations. When looking at the results of our one-dimensional hydrodynamic modelling study at Ammersee, it should be considered, that the hydrodynamic processes in the lake are obviously simplified (Bayer et al., 2013). Subsequently the model DYRESM for example underestimates water temperatures in the metalimnion and hypolimnion, as investigated during our calibration and validation period at Ammersee (Weinberger and Vetter, 2012). Also the meteorological data provided by the regional climate model REMO, which is derived from a global circulation model, may contain uncertainties in the estimation of the local climate. However these uncertainties can be minimised by a bias correction, as mentioned above. Additionally, even the measured meteorological data may contain measurement errors, which in turn could have an influence on the quality of the calibration process due to the model's strong sensitivity to these climatic input variables (Bueche and Vetter, 2013). Nevertheless, at Ammersee we showed that the models DYRESM and REMO can be used to identify potential drawbacks of climate change on the lake ecosystem (Weinberger and Vetter, 2012).

For the period between end of March and mid-November, an increase in lake heat content is projected (20412050) to occur in the upper $3 \mathrm{~m}$ of the epilimnion with respect to recorded values (1997-2007) (Fig. 1a). A similar rise in surface water temperatures has also been predicted by other limnological studies investigating the role of lakes as sentinels of climate change (Livingstone, 2003; Adrian et al., 2009; Ludovisi and Gaino, 2010; Schneider and Hook, 2010; Rimmer et al., 2011; Vetter and Sousa, 2012). The highest increase in Ammersee heat content was predicted, as expected, for the months of June to October. Both recorded and simulated maximum heat contents occur in August, which matches the findings of Livingstone (2003) for Lake Zurich. The fact, that winter water temperatures are expected to be lower in the period 2041-2050, is likely due to an underestimation of water temperatures by DYRESM (Weinberger and Vetter, 2012). However, this underestimation is of little importance to lake ecological development and thus will not be discussed further here. Whereas only minor changes in heat content between 3 and $10 \mathrm{~m}$ depth were projected to take place in future summer months (Fig. 1b), below $10 \mathrm{~m}$ (Fig. 1c), i.e. in the metalimnion and hypolimnion, a clear decrease was projected occurring from April to January. Only in February is heat content expected to remain nearly constant, with March the only month in which a merely slight decrease was simulated. The simulated development of total lake heat content (Fig. 1d) is expected to be similar, but with decreasing lev-

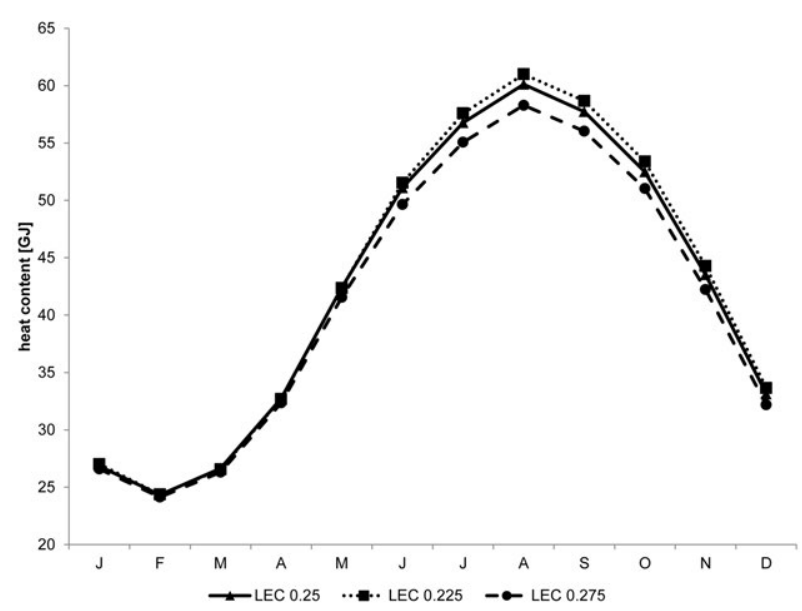

Fig. 5. Sensitivity of simulated heat content of the whole lake (2041-2050) to 10\% changes in DYRESM input parameter light extinction coefficient (LEC) $\left(\mathrm{m}^{-1}\right)$. 
els for the whole year until the period 2041-2050. These model results may at first seem surprising; in previous studies, the heat has been observed going beyond the barrier of the thermocline in recent years, suggesting that increasing heat content (even in the metalimnion and hypolimnion) could be a consequence of climate change (Dokulil et al., 2006; Ambrosetti et al., 2010). Therefore it was decided to divide the lake into different horizontal layers for further interpretation, making it possible to investigate the varying response of the water column to higher air temperatures, as well as the resulting heat content at different depths in the future. The predicted decrease in metalimnetic, hypolimnetic and total heat content in the present study could be the result of earlier establishment of a stable water column at higher epilimnetic and lower hypolimnetic temperatures (Livingstone, 2003). Hondzo and Stefan (1993) simulated that after climate change, hypolimnetic temperatures in seasonally-stratified dimictic lakes will be largely unchanged or even lower than at present, in agreement with our results. They also found their modelled data surprising, with the main reason suggested for the predicted values being a more rapid onset of stratification in early spring due to an increased net rate of surface heating after climate change; colder hypolimnetic water is thereby more quickly and effectively shielded from surface heating. Other authors with similar findings include Robertson and Ragotzkie (1990), who expected midsummer hypolimnion temperatures to change very little or increase only slightly in response to climatic warming.

Nevertheless, when calculating the heat content by means of the model DYRESM, the uncertainty based on the use of the modified version for freezing avoidance during the hydrodynamic simulation should be considered. The model DYRESM set back negative water temperatures to $0^{\circ} \mathrm{C}$ on 49 days during calibration and validation (2004-2007 and 1993-1999) and on 63 days during the future modelling period (2041-2050). Hence we assume that negative water temperatures will still appear in the period 2041 to 2050 and the ice-cover periods will be corresponding to those mentioned by Danis et al. (2004), who observed the duration of full ice-cover at Ammersee to be generally less than one month. Anyhow, it should be an objective for future studies at Ammersee, to investigate if the lake will still freeze over in the future and if there will be changes in frequency and duration of ice cover. These changes could have a strong influence on the mixing characteristics and hypolimnetic temperatures of the lake. For example, if the ice-cover disappears completely, there would be a potential for heat carry-over from one year to the next (Peeters et al., 2002) and for changes in the mixing regime of the lake from dimictic to monomictic. One explanation given earlier for the projected decrease in heat content at Ammersee was the potentially higher thermal stability of the water column, which would act as a barrier to heat entering the lake. This theory was verified after calculating Schmidt stability from field (1985 to 2007) and simulated (2041 to 2050) data, with thermal stability expected to be higher in the future for each month from April to November and the number of outliers (as defined in the boxplot chart) also increasing (Fig. 2, Tab. 2). Furthermore, the maximum value of lake thermal stability, which currently stands at the $7.70 \mathrm{kJm}^{-2}$ observed during the outstanding warm year of 2003, is simulated to be exceeded in the period 2041-2050.

The influence of changes in water temperature on lake density gradients and the resulting increase in water column thermal stability has been examined in a number of studies (MacIntyre et al. 2009; Williamson et al. 2009b; Rimmer et al. 2011). The main reason for increased thermal stability is typically a rise in surface water temperatures and a concomitant decrease or constancy in hypolimnetic temperatures, known as the vertical temperature gradient (Livingstone, 2003). Significantly, longterm changes in lake thermal structure may in the future be responsible for a shift in mixing regimes, changing nutrient and oxygen concentrations and thus also the vertical distribution and composition of lake biota (Adrian et al., 2009; Braig et al., 2010; Rempfer et al., 2010). Jankowski et al. (2006), for example, detected strong hypolimnetic oxygen depletion associated with an extremely high degree of thermal stability. As a result of increasing thermal stability, a greater quantity of energy derived from external forces will then be required to initialise complete mixing (Ambrosetti et al., 2010). Ammersee is predicted to be affected by a combination of lower heat content in the deeper layers and changes to the timing and duration of thermal stratification. According to a comparison of the projected stratification behaviour of the lake for the simulated period 2041-2050 with observed duration data recorded in 1985-2007, stratification is expected to occur earlier in spring and to last longer through autumn (Tab. 4, Fig. 3). A similar increase in the duration of stratification and reduced duration of winter mixing has also been detected elsewhere (Austin and Colman, 2008; Gaiser et al., 2009; MacKay et al., 2009; Rempfer et al., 2010). Although the simulated maximum duration of stratification at Ammersee was 204 days, no persistent lack of mixing was projected for the period 2041 to 2050 . Thus, the lake is estimated to remain dimictic, with complete mixing in autumn and spring and the occurrence of an inverse stratification in winter. Hence, no long-term increase in hypolimnetic water temperatures is visible. This result is different to that of Danis et al. (2004), who predicted an absence of mixing at Ammersee, which would irreversibly destroy deepwater fauna, occurring from the year 2020. The increase in stratification duration simulated in the present study approximately matches that of Livingstone (2003), who calculated an extension of 2 to 3 weeks. 
Other studies have also predicted long-term variation in thermocline depth as a result of changes in the water column density gradient, e.g. Adrian et al. (2009). Since the hydrodynamic model DYRESM satisfactorily reproduces the variability of water temperature profiles and seasonal thermocline, and also successfully models the metalimnion boundary (Perroud et al., 2009), it was decided in the present study to determine the extent of possible changes in thermocline and metalimnion depth (Fig. 4). The predicted future reduction in summer epilimnion thickness by Gaiser et al. (2009) and Rimmer et al. (2011) is in agreement with the modelling results presented here, simulating a decrease in the depth of the upper border of the metalimnion from May to September. In addition, our model results show a deepening of the thermocline from May to October. The limno-physical reasons for that are convective cooling and stronger vertical mixing, which are caused by increased wind speed. More precisely, the surface water temperatures and the thermal stability in autumn decrease and there is sufficient wind to initialise a vertical mixing of the water column. This was also detected by Livingstone (2003), who observed the deepest annual position of the thermocline in autumn. The mean thickness of the metalimnion in the present study was simulated to increase for the entire May to October period in the future (2041-2050), a pattern which contrasts with the findings of Rimmer et al. (2011) who observed a decrease in metalimnion thickness between 1969 and 2008. The mean depth of the thermocline at Ammersee could in the future be situated above its historically-recorded vertical May-June position. This change could be due to increased heat input into the lake, as previously mentioned by Tanentzap et al. (2007) and as predicted in a number of regional climate models. However, the vertical position of the thermocline in July is projected to remain constant, a result similar to that of Robertson and Ragotzkie (1990), who simulated both no change in thermocline depth during midsummer and a shallower position in autumn. This latter prediction was also determined in the present study, with mean thermocline depth projected to increase between the beginnings of August to October with respect to observed data (1985-2007).

In this paper, it was also possible to show that the modelled physical properties of the lake are sensitive to a $10 \%$ change in light extinction coefficient (LEC) of the water. Our findings, that higher LEC results in increasing modelled surface water temperatures in spring and summer as well as in decreasing water temperatures in the metalimnion and hypolimnion (below $10 \mathrm{~m}$ ) for the same period, are in line with the results of previous studies. In general it can be said that the LEC is known to affect the vertical distribution of heat in the water column (Tanentzap et al., 2008; Rinke et al., 2010). Also the lower heat content of the whole lake (Fig. 5) and the stronger stratification of the water column with increasing LEC were already detected in aforementioned studies. Since LEC describes water transparency, which is subject to ecological conditions in the lake, the physical properties of lakes are not only the basis to simulate ecological conditions, but also are affected by changes in the trophic state of the water body.

\section{CONCLUSIONS}

The coupling of regional climate and hydrodynamic models enables forward-looking statements to be made regarding the limnological impact of climate change. Although the results obtained via this method are of course just estimations, such coupling remains yet the only available tool with which to assess the aforementioned effects. In the present study, it was possible to elucidate a wide range of limno-physical consequences that can be investigated by the use of these models, with a concrete examination made of an important mid-European, comparatively large fresh water body. Evaluation of the relevant literature reveals that the impact of a changing climate on the lake's hypolimnetic heat content is particularly contested and should thus be explored further using new modelling techniques. In our opinion and according to the presented simulation results, the hypolimnetic heat content of Ammersee will experience a clear decrease in the future due to higher thermal stability in the water column. Anyhow, we estimate that the mixing type of Ammersee will remain dimictic. Additionally, it is essential that further limnological research is conducted to assess the impact of changes in ice cover as well as to allow a coupling of the hydrodynamic model with an ecological model of the lake. It is therefore also advisable to conduct and assess carefully calibrated and validated limno-physical modelling. The present study represents a sound basis for such modelling, with the employed methods recommendable for other members of the lake ecosystem modelling community (Mooij et al., 2010).

\section{ACKNOWLEDGMENTS}

We would like to thank the Chair of Geography and Landscape Ecology at the University of Munich, Professor O. Baume, for his support and for providing such a comfortable working environment. We are also deeply grateful to the Bavarian Environmental Agency for funding our LAGO project, and to Dr. Karsten Rinke at the Helmholtz Centre for Environmental Research (UFZ) for his valuable advice and the organization of lake Modeller meetings. Finally, thanks go to the Centre for Water Research at the University of Western Australia for providing the model DYRESM, Sascha Jackisch from the University of Munich for his support, and the anonymous reviewers of this manuscript for their helpful comments. 


\section{REFERENCES}

Adrian R, O'Reilly CM, Zagarese H, Baines SB, Hessen DO, Keller W, Livingstone DM, Sommaruga R, Straile D, Van Donk E, Weyhenmeyer GA, Winder M, 2009. Lakes as sentinels of climate change. Limnol. Oceanogr. 54:2283-2297.

Ambrosetti W, Barbanti L, 2005. Evolution towards meromixis of Lake Iseo (Northern Italy) as revealed by its stability trend. J. Limnol. 64:1-11.

Ambrosetti W, Barbanti L, Carrara EA, 2010. Mechanisms of hypolimnion erosion in a deep lake (Lago Maggiore, N. Italy). J. Limnol. 69:3-14.

Antenucci J, Horn D, 2002. DYRESM: dynamic reservoir simulation model. Water 29:93-96.

Austin J, Colman S, 2008. A century of temperature variability in Lake Superior. Limnol. Oceanogr. 53:2724-2730.

Bates B, Kundzewicz Z, Wu S, Palutikof J, 2008. Climate change and water. Intergovernmental Panel on Climate Change ed., Geneva: 210 pp.

Bayer T, Burns C, Schallenberg M, 2013. Application of a numerical model to predict impacts of climate change on water temperatures in two deep, oligotrophic lakes in New Zealand. Hydrobiologia 713:53-71.

Birge EA, 1897. Plankton studies on Lake Mendota, II. Transactions of the Wisconsin Academy of Science. Wisconsin Academy of Sciences, Madison: 239 pp.

Braig E, Welzl G, Stichler W, Raeder U, Melzer A, 2010. Entrainment, annual circulation and groundwater inflow in a chain of lakes as inferred by stable (18)O isotopic signatures in the water column. J. Limnol. 69:278-286.

Bueche T, Vetter M, 2013. Simulating water temperatures and stratification of a pre-alpine lake with a hydrodynamic model: calibration and sensitivity analysis of climatic input parameters. Hydrol. Process. 28:1450-1464.

Chen CT, Millero FJ, 1986. Precise thermodynamic properties for natural waters covering only the limnological range. Limnol. Oceanogr. 31:657-662.

Coats R, Perez-Losada J, Schladow G, Richards R, Goldman C, 2006. The warming of Lake Tahoe. Climatic Change 76:121-148.

Danis PA, von Grafenstein U, Masson-Delmotte V, Planton S, Gerdeaux D, Moisselin JM, 2004. Vulnerability of two European lakes in response to future climatic changes. Geophys. Res. Lett. 31:L21507.

Dokulil MT, Jagsch A, George GD, Anneville O, Jankowski T, Wahl B, Lenhart B, Blenckner T, Teubner K, 2006. Twenty years of spatially coherent deepwater warming in lakes across Europe related to the North Atlantic oscillation. Limnol. Oceanogr. 51:2787-2793.

Ernst B, Hoeger SJ, O’Brien E, Dietrich DR, 2009. Abundance and toxicity of Planktothrix rubescens in the pre-alpine Lake Ammersee, Germany. Harmful Algae 8:329-342.

Fang X, Stefan HG, 2009. Simulations of climate effects on water temperature, dissolved oxygen, and ice and snow covers in lakes of the contiguous United States under past and future climate scenarios. Limnol. Oceanogr. 54:2359-2370.

Gaiser EE, Deyrup ND, Bachmann RW, Battoe LE, Swain HM, 2009. Effects of climate variability on transparency and thermal structure in subtropical, monomictic Lake Annie, Florida. Fund. Appl. Limnol. 175:217-230.

Gal G, Imberger J, Zohary T, Antenucci J, Anis A, Rosenberg T,
2003. Simulating the thermal dynamics of Lake Kinneret. Ecol. Model. 162:69-86.

Gallina N, Anneville O, Beniston M, 2011. Impacts of extreme air temperatures on cyanobacteria in five deep peri-Alpine lakes. J. Limnol. 70:186-196.

Han BP, Armengol J, Garcia JC, Comerma M, Roura M, Dolzc J, Straskrabad M, 2000. The thermal structure of Sau Reservoir (NE:Spain): a simulation approach. Ecol. Model. 125:109-122.

Hondzo M, Stefan H, 1993. Regional water temperature characteristics of lakes subjected to climate change. Climatic Change 24:187-211.

Huber V, Adrian R, Gerten D, 2008. Phytoplankton response to climate warming modified by trophic state. Limnol. Oceanogr. 53:1-13.

Hutchinson GE, 1957. A treatise on limnology. J. Wiley \& Sons, New York: $1015 \mathrm{pp}$.

Imberger J, Patterson JC, 1981. A Dynamic Reservoir Simulation Model - DYRESM 5, p. 310-361. In: H.B. Fischer (ed.), Transport models for inland and coastal waters. Academic Press.

Imerito A, 2007. Dynamic reservoir simulation model DYRESM v4. Centre of Water Research, University of Western Australia: 41 pp.

Jacob D, Bärring L, Christensen O, Christensen J, Castro M, Déqué M, Giorgi F, Hagemann S, Hirschi M, Jones R, Kjellström E, Lenderink G, Rockel B, Sánchez E, Schär C, Seneviratne SI, Somot S, van Ulden A, van den Hurk B, 2007. An inter-comparison of regional climate models for Europe: model performance in present-day climate. Climatic Change 81:31-52.

Jankowski T, Livingstone DM, Buhrer H, Forster R, Niederhauser P, 2006. Consequences of the 2003 European heat wave for lake temperature profiles, thermal stability, and hypolimnetic oxygen depletion: implications for a warmer world. Limnol. Oceanogr. 51:815-819.

Joehnk KD, Umlauf L, 2001. Modelling the metalimnetic oxygen minimum in a medium sized alpine lake. Ecol. Model. 136:67-80.

Kirilova E, Heiri O, Enters D, Cremer H, Lotter AF, Zolitschka B, Hübener T, 2009. Climate-induced changes in the trophic status of a Central European lake. J. Limnol. 68:71-82.

Kucklentz V, 2001. [Antwort bayerischer Voralpenseen auf verringerte Nährstoffzufuhr]. [Book in German]. Bayerisches Landesamt für Wasserwirtschaft, München: 272 pp.

Legates DR, McCabe GJ Jr, 1999. Evaluating the use of "goodness-of-fit" Measures in hydrologic and hydroclimatic model validation. Water Resour. Res. 35:233-241.

Livingstone DM, 2003. Impact of secular climate change on the thermal structure of a large temperate central European lake. Climatic Change 57:205-225.

Ludovisi A, Gaino E, 2010. Meteorological and water quality changes in Lake Trasimeno (Umbria, Italy) during the last fifty years. J. Limnol. 69:174-188.

MacIntyre S, Fram JP, Kushner PJ, Bettez ND, O'Brien WJ, Hobbie JE, Kling GW, 2009. Climate-related variations in mixing dynamics in an Alaskan arctic lake. Limnol. Oceanogr. 54: 2401-2417.

MacKay MD, Neale PJ, Arp CD, Domis LNDS, Fang X, Gal G, Johnk KD, Kirillin G, Lenters JD, Litchman E, Macintyre 
S, Marsh P, Melack J, Mooij WM, Peeters F, Quesada A, Schladow SG, Schmid M, Spence C, Stokesr SL, 2009. Modeling lakes and reservoirs in the climate system. Limnol. Oceanogr. 54:2315-2329.

Mooij WM, Trolle D, Jeppesen E, Arhonditsis G, Belolipetsky PV, Chitamwebwa DBR, Degermendzhy AG, DeAngelis DL, De Senerpont Domis LN, Downing AS, Elliott JA, Fragoso CR Jr, Gaedke U, Genova SN, Gulati RD, Håkanson L, Hamilton DP, Hipsey MR, 't Hoen J, Hülsmann S, Los FH, Makler-Pick V, Petzoldt T, Prokopkin IG, Rinke K, Schep SA, Tominaga K, Van Dam AA, Van Nes EH, Wells SA, Janse JH, 2010. Challenges and opportunities for integrating lake ecosystem modelling approaches. Aquat. Ecol. 44:633-667.

Mudelsee M, Chirila D, Deutschländer T, Döring K, Haerter J, Hagemann S, Hoffmann H, Jacob D, Krahe P, Lohmann G, Moseley C, Nilson E, Panferov O, Rath T, Tinz B, 2010. [Climate Model Bias Correction und die Deutsche Anpassungsstrategie]. [Article in German]. Mitteilungen DMG 3:2-7.

Nakicenovic N, Davisdson O, Davis G, Grübler A, Kram T, 2000. IPCC special report emissions scenarios. IPCC Secretary, Geneva: $22 \mathrm{pp}$.

Niedda M, Pirastru M, 2013. Hydrological processes of a closed catchment-lake system in a semi-arid Mediterranean environment. Hydrol. Process. 27:3617-3626.

Peeters F, Livingstone DM, Goudsmit GH, Kipfer R, Forster R, 2002. Modeling 50 years of historical temperature profiles in a large central European lake. Limnol. Oceanogr. 47:186-197.

Perroud M, Goyette S, Martynov A, Beniston M, Anneville O, 2009. Simulation of multiannual thermal profiles in deep Lake Geneva: a comparison of one-dimensional lake models. Limnol. Oceanogr. 54:1574-1594.

Piani C, Haerter JO, Coppola E, 2009. Statistical bias correction for daily precipitation in regional climate models over Europe. Theor. Appl. Climatol. 99:187-192.

Rempfer J, Livingstone DM, Blodau C, Forster R, Niederhauser P, Kipfer R, 2010. The effect of the exceptionally mild European winter of 2006-2007 on temperature and oxygen profiles in lakes in Switzerland: a foretaste of the future? Limnol. Oceanogr. 55:2170-2180.

Rimmer A, Gal G, Opher T, Lechinsky Y, Yacobi YZ, 2011. Mechanisms of long-term variations of thermal structure in a warm lake. Limnol. Oceanogr. 56:974-988.

Rinke K, Yeates P, Rothhaupt KO, 2010. A simulation study of the feedback of phytoplankton on thermal structure via light extinction. Freshwater Biol. 55:1674-1693.

Robertson D, Ragotzkie R, 1990. Changes in the thermal structure of moderate to large sized lakes in response to changes in air temperature. Aquat. Sci. 52:360-380.

Romero JR, Antenucci JP, Imberger J, 2004. One- and three-dimensional biogeochemical simulations of two differing reservoirs. Ecol. Model. 174:143-160.

Samuelsson P, 2010. Using regional climate models to quantify the impact of climate change on lakes, p. 15-32. In: G. George (ed.), The impact of climate change on European lakes. Springer.

Schneider P, Hook SJ, 2010. Space observations of inland water bodies show rapid surface warming since 1985. Geophys. Res. Lett. 37:L22405.

Schwoerbel J, Brendelberger H, 2005. [Einführung in die Limnologie]. [Book in German]. Spektrum Akademischer Verlag, München: 340 pp.

Solomon S, Quin D, Manning M, Chen Z, Marquis M, Averyt KB, Tignor M, Miller HL, 2007. Climate Change 2007. The physical science basis: contribution of working group I to the fourth assessment report of the IPCC. Cambridge University Press, Cambridge: 996 pp.

Tanentzap AJ, Hamilton DP, Yan ND, 2007. Calibrating the Dynamic Reservoir Simulation Model (DYRESM) and filling required data gaps for one-dimensional thermal profile predictions in a boreal lake. Limnol. Oceanogr. 5:484-494.

Tanentzap AJ, Yan ND, Keller B, Girard R, Heneberry J, 2008. Cooling lakes while the world warms: effects of forest regrowth and increased dissolved organic matter on the thermal regime of a temperate, urban lake. Limnol. Oceanogr. 53:404-410.

Terink W, Hurkmans RTWL, Torfs PJJF, Uijlenhoet R, 2010. Evaluation of a bias correction method applied to downscaled precipitation and temperature reanalysis data for the Rhine basin. Hydrol. Earth Syst. Sc. 14:687-703.

Trolle D, Hamilton DP, Pilditch CA, Duggan IC, Jeppesen E, 2011. Predicting the effects of climate change on trophic status of three morphologically varying lakes: implications for lake restoration and management. Environ. Modell. Softw. 26:354-370.

Trolle D, Jørgensen TB, Jeppesen E, 2008. Predicting the effects of reduced external nitrogen loading on the nitrogen dynamics and ecological state of deep Lake Ravn, Denmark, using the DYRESM-CAEDYM model. Limnologica 38:220-232.

UNESCO, 1987. International oceanographic tables. UNESCO technical papers in marine science. UNESCO, Paris: 196 pp.

Vetter M, Sousa A, 2012. Past and current trophic development in Lake Ammersee - Alterations in a normal range or possible signals of climate change? Fund. Appl. Limnol. 180:41-57.

Wagner C, Adrian R, 2009. Cyanobacteria dominance: quantifying the effects of climate change. Limnol. Oceanogr. 54:2460-2468.

Weinberger S, Vetter M, 2012. Using the hydrodynamic model DYRESM based on results of a regional climate model to estimate water temperature changes at Lake Ammersee. Ecol. Model. 244:38-48.

Williamson CE, Saros JE, Schindler DW, 2009a. Sentinels of change. Science 323:887-888.

Williamson CE, Saros JE, Vincent WF, Smol JP, 2009b. Lakes and reservoirs as sentinels, integrators, and regulators of climate change. Limnol. Oceanogr. 54:2273-2282. 